Research Article

\title{
Obtaining Hydrophobic Aerogels of Unbleached Cellulose Nanofibers of the Species Eucalyptus sp. and Pinus elliottii
}

\author{
Márcia Zanini (iD, ${ }^{1}$ Alessandra Lavoratti $\left(\mathbb{D},{ }^{2}\right.$ Lídia Kunz Lazzari, ${ }^{1}$ Deise Galiotto, ${ }^{1}$ \\ Camila Baldasso, ${ }^{1}$ and Ademir José Zattera ${ }^{1}$ \\ ${ }^{1}$ Postgraduate Program in Engineering of Processes and Technologies (PGEPROTEC), University of Caxias do Sul (UCS), 95070- \\ 490 Caxias do Sul, RS, Brazil \\ ${ }^{2}$ Postgraduate Program in Mining, Metallurgical, and Materials Engineering (PPGE3M), Federal University of Rio Grande do \\ Sul (UFRGS), Av. Bento Gonçalves 9500, 91501-970 Porto Alegre, RS, Brazil
}

Correspondence should be addressed to Márcia Zanini; mzanini.marcia@gmail.com

Received 30 May 2018; Revised 16 August 2018; Accepted 26 August 2018; Published 11 October 2018

Academic Editor: Ilaria Armentano

Copyright ( 2018 Márcia Zanini et al. This is an open access article distributed under the Creative Commons Attribution License, which permits unrestricted use, distribution, and reproduction in any medium, provided the original work is properly cited.

\begin{abstract}
The use of natural fibers from renewable and biodegradable sources in oleophilic sorbents, such as cellulose, has become an interesting alternative due to their excellent properties and sustainability. In addition to that, the low density of the aerogels obtained from cellulose is favorable for their use as sorbents. In this context, the objective of this study is to develop hydrophobic aerogels of unbleached cellulose nanofibers of the Eucalyptus sp. and Pinus elliottii. Cellulose samples were submitted to mechanical fibrillation to obtain cellulose nanofiber suspensions, followed by a chemical treatment with methyltrimethoxysilane and dried by freeze-drying to prepare the aerogels. The aerogels presented hydrophobic and oleophilic characteristics, including a water contact angle of $134^{\circ}$, sorption capacities in a heterogeneous medium of above $21.0 \mathrm{~g} \cdot \mathrm{g}^{-1}$, and oil removal efficiency greater than $88.5 \%$. The Pinus elliottii nanofiber aerogels showed higher compressive strength when compared to the nanofiber aerogels of Eucalyptus sp.
\end{abstract}

\section{Introduction}

Water contamination by oil spills causes major environmental impacts. The consequences of these accidents can generate short-, medium-, and long-term impacts to the environment, as well as permanent and irreversible damage to the local ecosystem, affecting the environment and human health [1].

The International Tanker Owners Pollution Federation is an organization which has a database of oil spills from oil tankers, transporters, and combined vessels. Accidents with oil spills are generally classified by the amount of oil spilled, such as small (less than 7 tons), medium (7-700 tons), and large (over 700 tons). According to statistics provided by this organization, in 2016 incidents considered small accounted for $81 \%$ of the occurrences. A large oil tank spill in the Gulf of Mexico with a cargo of approximately 5500 tons of gasoline and diesel, and four medium-sized spills of various oils, including crude oil, were also recorded. However, the total amount of oil spilled in the marine environment in 2016 was approximately 6000 tons [2].

The most used strategies for the treatment of water contaminated with oil are as follows: oil extraction at the surface of the water, dispersion of the oil in the water with the use of chemical dispersants to facilitate natural degradation, and oil burning [3-5]. For the extraction of oil in water, the use of sorbents is considered a promising alternative due to the simplicity of the method. They can be used in the open sea, and the availability of automated systems minimizes workers' exposure to chemical and toxic substances produced. There is also the possibility of recovering the oil, thus generating less environmental impact $[5,6]$.

Oleophilic sorbents derived from renewable-source fibers, such as cellulose, can be promising alternatives in the treatment of oil-contaminated water. There is an increasing interest in research pertaining to the production of cellulosic 
oleophilic sorbents, since cellulose is the most abundant biopolymer of the planet from renewable sources. Cellulose is characterized as a linear polysaccharide consisting of D-glucose units linked together alternately, with its repeating unit called cellobiose, which is also present in plants, animals, and some bacteria. Wood is the main source of its production [7-10]. In Brazil, the main sources of cellulose are planted forests of the Pinus sp. and Eucalyptus sp., responsible for more than $98 \%$ of the national production [11]. Wood pulp fibers are one of the main source materials in several research areas, because they can be used for a number of applications, including reinforcement in composites, bioenergy feedstocks, source materials for biochemical production, and oleophilic sorbents [12, 13].

Cellulose nanofibers (CNFs) are the smallest structures of the plant fibers. They have a nanometric diameter and a micrometric scale length, and a crystalline structure which alternates with amorphous domains [14-16]. CNFs present high stiffness, good tensile strength, and high surface area $[17,18]$. These nanofibers are mainly obtained by the mechanical fibrillation of the wood pulp [19], and can be used as constituents of porous materials, such as filters and sorbents [20].

Aerogels are solid, highly porous, and low-density materials from a suspension that has undergone a drying process in which the solvent is replaced by a gas without changing its molecular structure. For extraction of the solvent, it is necessary to subject it to a drying process, mainly using freezedrying or supercritical drying [21]. Aerogels of cellulose nanofibers are highly resistant materials, with a low density, high rate of sorption, and high surface area. They have excellent properties to be used as oleophilic sorbents; however, it is necessary to subject these sorbents to a chemical treatment to obtain a hydrophobic and oleophilic material [22, 23].

Many studies report obtaining cellulose aerogels with the addition of chemical solvents, for example, sodium hydroxide solutions, sodium hydroxide/urea solutions, N-methylmorpholine-N-oxide (NMMO), and calcium thiocyanate solutions [21]. Jin et al. [24] prepared aerogels from waste paper without pretreatment, using only 1-allyl-3-methyimidazolium chloride as a solvent to dissolve the material and freeze-drying it.

Some studies on obtaining aerogels without the use of solvents have already been published. Korhonen et al. [3] made aerogels from a cellulose nanofiber suspension of homogenized hardwood kraft pulp, followed by freezedrying and chemical functionalization with titanium dioxide. Zanini et al. [25] reported in their studies the obtainment of aerogels of bleached CNFs of the Eucalyptus sp. species without adding chemical solvents. Lazzari et al. [26] also obtained aerogels of unbleached CNFs of the Pinus elliottii species without the addition of solvents.

The novelty of this research is the obtainment and evaluation of the sorption capacities of hydrophobic aerogels from unbleached CNFs of Eucalyptus sp. and Pinus elliottii without the addition of chemical solvents. Moreover, the use of unbleached cellulose waste could be advantageous to the production of these aerogels, since no bleaching process would be required, therefore generating fewer waste. In this study, the aerogels were obtained from mechanically fibrillated CNF suspensions. The contact angle, sorption capacity, and compressive strength were evaluated.

\section{Materials and Methods}

2.1. Materials. The following materials were used for the preparation of the aerogels: unbleached cellulose of Eucalyptus sp. (CE), unbleached cellulose of Pinus elliottii (CP) (both $\mathrm{CE}$ and $\mathrm{CP}$ were supplied by Rio Grande Companhia de Celulose do Sul, RS, Brazil), glacial acetic acid (provided by Neon), and methyltrimethoxysilane (MTMS) (98\% purity purchased from Sigma-Aldrich). For the sorption experiments, SAE 20W50 motor oil with a viscosity of $64 \mathrm{cSt}$ and a density of $0.88 \mathrm{~g} \cdot \mathrm{cm}^{-3}\left(20-40^{\circ} \mathrm{C}\right)$ was provided by Ipiranga Petrochemical (RS, Brazil). This oil was classified as a medium oil, according to ASTM F726-12.

\subsection{Methods}

2.2.1. Production of the Aerogels. Cellulose fibrillation was performed by a mechanical process. The pulp was dispersed in distilled water with an initial concentration of $3 \%(\mathrm{wt} \% / \mathrm{v} \%)$. Grinding was conducted in a Masuko Sangyo stone disc mill, model MKCA6-2J with an adapted recirculation pump, for 5 hours with a rotation speed of $2500 \mathrm{rpm}$. Figure 1(a) illustrates the mechanical grinding.

In order to obtain the aerogels' hydrophobic properties, a chemical treatment of the suspensions with the use of the methyltrimethoxysilane (MTMS) was carried out at a concentration of $2 \%$ in mass, according to our previous work [25]. The CNF suspension was filtered through a vacuum system. The permeate $\mathrm{pH}$ was then adjusted to 3.0 by adding acetic acid under magnetic stirring for $5 \mathrm{~min}$. Subsequently, $2 \%$ in mass of MTMS was added to this solution under magnetic stirring. The resulting solutions were slowly added dropwise into the MTMS supernatant filtration. The CNF suspension with MTMS was mechanically stirred at $500 \mathrm{rpm}$ for 1 hour and kept in an oven at $70^{\circ} \mathrm{C}$ for 2 hours, as shown in Figure 1(b).

Triplicates of the samples obtained in the chemical treatment were placed in cylindrical molds and frozen to $-80^{\circ} \mathrm{C}$ for 24 hours. They were then transferred to a vacuum chamber for freeze-drying for 72 hours, as shown in Figure 1(c). Finally, Figure 1(d) shows the cellulose aerogels.

2.2.2. Sample Characterization. Cellulose was characterized in relation to its $\alpha$-, $\beta$-, and $\gamma$-cellulose content according to TAPPI T203 standards. Scanning electron microscopy with field emission gun (FEG-SEM - MIRA 3, Tescan) was used for morphological characterization.

The determination of the apparent density of the aerogels obtained by freeze-drying and cellulose (as received) was performed by an adaptation of ASTM D3575-14 standards, by measuring the volume and the mass of the obtained aerogels, according to (1). Three samples were measured.

$$
\text { Density }=\frac{\text { mass }}{\text { volume }} \text {. }
$$




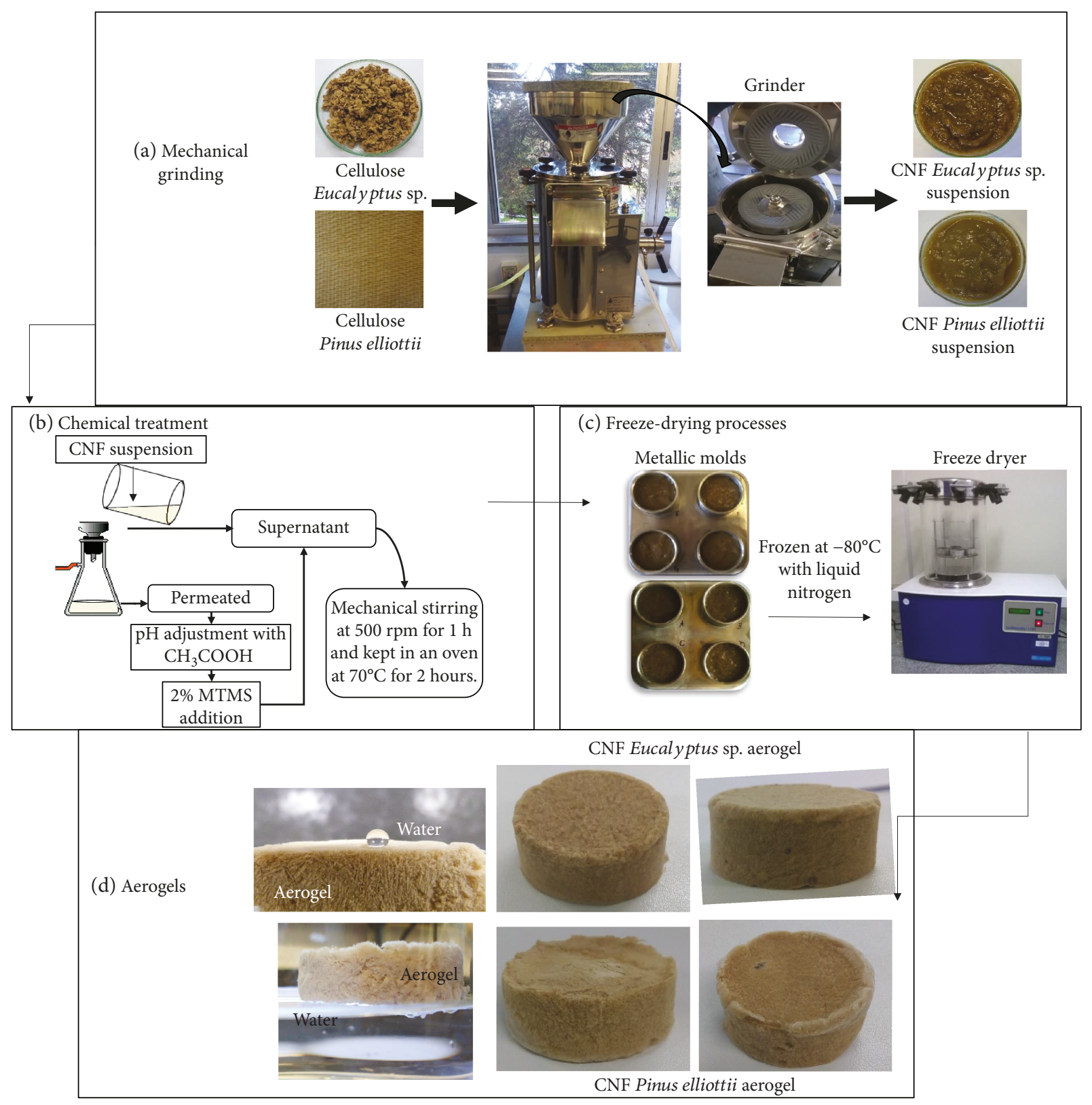

Figure 1: Process for obtaining aerogels: (a) mechanical grinding, (b) chemical treatment, (c) freeze-drying process, and (d) aerogels.

The porosity of the aerogels can be obtained by (2), which relates the density of the cellulose to the obtained aerogel. Triplicates were performed.

$$
\text { Porosity }=1-\frac{\text { density of aerogel }}{\text { density of cellulose }}
$$

Compressive strength tests were performed in a universal EMIC test equipment, model DL 2000, with a compression speed of $1.3 \mathrm{~mm} \cdot \mathrm{min}^{-1}$. The tension required to reduce the thickness of the specimen by up to $50 \%$ of its initial thickness was measured, as adapted from ASTM D695-15 standards.

The modification on the aerogel surface was investigated by Fourier transform infrared spectroscopy (FTIR) in a
Nicolet iS10 Thermo Scientific equipment. Each spectrum was obtained by performing 32 scans by attenuated total reflectance (ATR). The wavenumber analyzed ranged from $400 \mathrm{~cm}^{-1}$ to $4000 \mathrm{~cm}^{-1}$.

Fast sorption tests in homogeneous medium were performed, adapted from ASTM F726-12. Samples were weighted and placed in homogeneous media (either water or oil) for $15 \pm 0.5$ minutes. After that, aerogels were vertically removed from the media, drained for $30 \pm 2$ seconds, and then weighted. Triplicates were performed. The sorption capacity results were calculated as follows:

$$
\mathrm{CA}=\frac{m_{f}-m_{i}}{m_{i}}
$$


where CA is sorption capacity $\left(\mathrm{g} \cdot \mathrm{g}^{-1}\right), m_{i}$ is initial mass $(\mathrm{g})$, and $m_{f}$ is final mass $(\mathrm{g})$.

The water contact angle measurement was obtained through the sessile drop method, in distilled water, with an approximate droplet volume of $5 \mu \mathrm{L}$. Samples were placed on a glass slide at $25 \pm 2^{\circ} \mathrm{C}$ and relative humidity of $60 \pm 5 \%$. Three droplets of water were placed on the top of the samples. Pictures were taken every 15 minutes for 30 minutes and the images were analyzed with the SURFTENS software.

The quantity of oil previously estimated from homogeneous media tests in oil was added to a Petri dish with $200 \mathrm{~mL}$ of distilled water. After that, aerogels were placed in the heterogeneous medium for $15 \pm 0.5$ minutes. The sorbent was removed from the oil in a vertical orientation with a clip, leaving it to drain for $30 \pm 2$ seconds and weighted, according to the ASTM F726-12 standard adaptation. Assays were performed with 3 samples and the amount of oil adsorbed is given by (2). This method was adapted from Zhang et al. [4] and Nguyen et al. [27].

\section{Results and Discussion}

3.1. Characterization of Cellulose Samples. The $\alpha$-cellulose, $\beta$-cellulose, $\gamma$-cellulose, and lignin contents of the samples are shown in Table 1.

The CE sample presented a higher lignin content and lower percentage of $\alpha$-cellulose compared to CP. Chen et al. [28] found a 24.4\% lignin mass content for Eucalyptus sp. wood. Gomide et al. [29] found $\alpha$-cellulose contents ranging from 43.9 to $49.7 \%$ and lignin contents ranging from 27.5 to $31.7 \%$ in Eucalyptus sp. wood used in their studies. Pinus elliotti species presented lignin contents ranging from 32.8 to $35 \%$. According to Klock et al. [30], in long-fiber woods such as Pinus elliotti, the average composition of wood pulp varies from 40 to $44 \%$.

The percentages of $\mathrm{CE}$ and $\mathrm{CP}$ lignin used in this work were lower when compared to the original wood. The percentages of $\alpha$-cellulose of the same samples, when compared with the original wood, were higher due to the process used to obtain the samples. During this process, the extractives, husks, and part of the lignin were removed.

Figure 2 shows the FEG-SEM micrographs of the CE and CP cellulose samples, with magnifications of 150x and 1000x. A set of compact fibers in macro/micrometric scale is observed, as well as long filaments and linear structures coming from intramolecular hydrogen bonds between hydroxyl groups of the same molecules, resulting in a straight and rigid polymer chain [31]. It is also observed that CP cellulose has fibers with seemingly larger diameters than CE cellulose.

The apparent density values of cellulose samples were $0.198 \pm 0.010 \mathrm{~g} \cdot \mathrm{cm}^{-3}$ for CE and $0.414 \pm 0.011 \mathrm{~g} \cdot \mathrm{cm}^{-3}$ for $\mathrm{CP}$. CP has the lowest apparent density, as well as the smallest compaction of fibers when compared to the $\mathrm{CP}$ cellulose sample.

3.2. Development of Aerogels. The mechanical process promoted the cellulose fibrillation, resulting in homogeneous suspensions, which can be seen in Figure 1(a). Differently from chemical processes, this process presents less
Table 1: Percentages of $\alpha$-cellulose, $\beta$-cellulose, $\gamma$-cellulose, and lignin of the cellulose samples.

\begin{tabular}{lcccc}
\hline Samples & $\begin{array}{c}\alpha \text {-Cellulose } \\
(\%)\end{array}$ & $\begin{array}{c}\beta \text {-Cellulose } \\
(\%)\end{array}$ & $\begin{array}{c}\gamma \text {-Cellulose } \\
(\%)\end{array}$ & $\begin{array}{c}\text { Lignin } \\
(\%)\end{array}$ \\
\hline $\mathrm{CE}$ & $57.34 \pm 0.18$ & $16.48 \pm 0.27$ & $0.74 \pm 0.01$ & $14.18 \pm 0.02$ \\
$\mathrm{CP}$ & $60.2 \pm 0.27$ & $13.33 \pm 0.17$ & $0.84 \pm 0.01$ & $5.69 \pm 0.02$ \\
\hline
\end{tabular}

environmental impact while also allowing the obtainment of CNFs from an aqueous solution suspension of cellulose fibers without the addition of chemical compounds. According to Peng et al. [32], a uniform aqueous suspension of CNFs is formed after fibrillation in which the strong hydrogen bonds between water and cellulose particles allow the system to remain stable. In the mechanical process, the shear forces of disintegration and the high degree of fibrillation provide the obtainment of interconnected fibrils with a diameter of less than $100 \mathrm{~nm}$ in width and length in the micrometric scale $[33,34]$.

The final contents of cellulose in the suspension of $\mathrm{CE}$ and $\mathrm{CP}$ were, respectively, $2.449 \pm 0.02 \%$ and $2.304 \pm 0.05 \%$ in cellulose mass. The values found herein were lower than the initial ones (3.0\% in mass) due to losses during the grinding process.

The aerogels did not present a retraction in relation to the initial volume of the suspensions of CNF, thus acquiring the format of the cylindrical mold used. According to Shi et al. [35], the volume shrinkage of aerogels reflects the efficiency of the drying method. Figure 1(d) shows the aerogels obtained from CE and CP suspensions, showing homogeneity in their structures, and no discoloration. CNF aerogels obtained by Chen et al. [36] also maintained their volumes after freeze-drying, without shrinkage. According to Nguyen et al. [27], cellulose aerogels are formed by hydrogen bonds and by the self-assembly process of the cellulose fibers.

3.3. Apparent Density and Porosity. The apparent density values of the aerogels obtained varied from $0.030 \mathrm{~g} \cdot \mathrm{cm}^{-3}$ to $0.032 \mathrm{~g} \cdot \mathrm{cm}^{-3}$. These values are directly related to the fiber content present, as well as to its production process.

Mechanical fibrillation and freeze-drying processes yielded $\mathrm{CE}$ and $\mathrm{CP}$ aerogels with decreased densities based on the source of the cellulose, that is, from $0.198 \pm 0.0125 \mathrm{~g} \cdot \mathrm{cm}^{-3}$ to $0.030 \pm 0.0011 \mathrm{~g} \cdot \mathrm{cm}^{-3}$, and from $0.414 \pm 0.0109 \mathrm{~g} \cdot \mathrm{cm}^{-3}$ to $0.032 \pm 0.0022 \mathrm{~g} \cdot \mathrm{cm}^{-3}$, respectively. $\mathrm{CP}$ aerogels showed the lowest density due to being derived from lower density cellulose.

$\mathrm{CP}$ aerogels presented a higher porosity $(92.2 \%)$, while $\mathrm{CE}$ aerogels presented values of $85.3 \%$, due to the $\mathrm{CE}$ cellulose having a lower density, being less compacted when compared to $\mathrm{CP}$.

Values found in relation to the apparent density and porosity are in agreement with studies already published by other authors. Pääkkö et al. [37] and Korhonen et al. [3] described a nanocellulose aerogel with a density between 0.02 and $0.03 \mathrm{~g} \cdot \mathrm{cm}^{-3}$ and a porosity of $98 \%$. Aerogels were obtained from a nanocellulose hydrogel (mechanically homogenized hardwood kraft pulp, dry content about 2\%) 


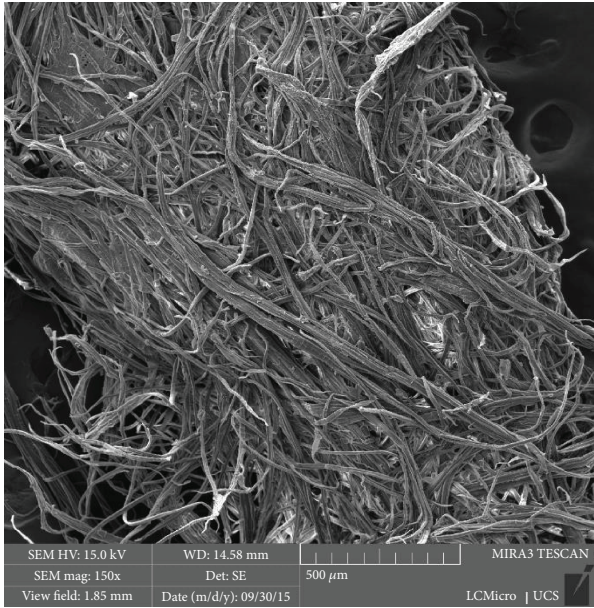

(a)

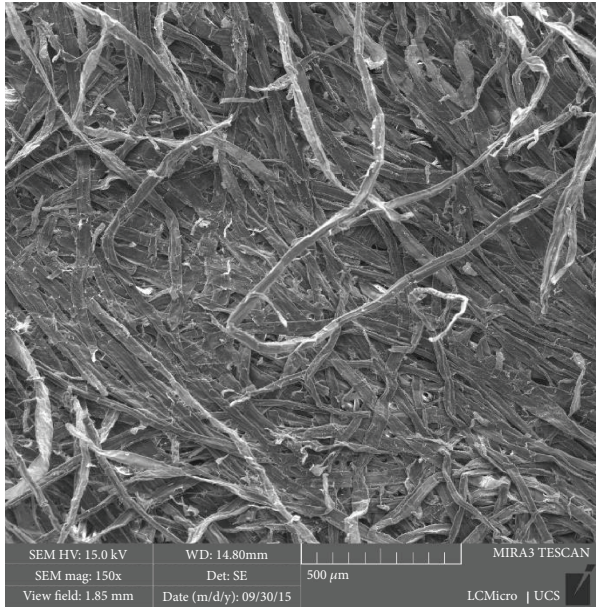

(c)

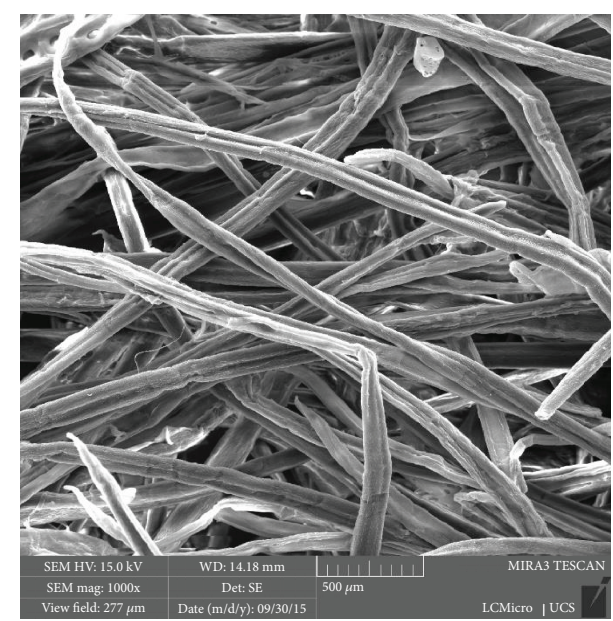

(b)

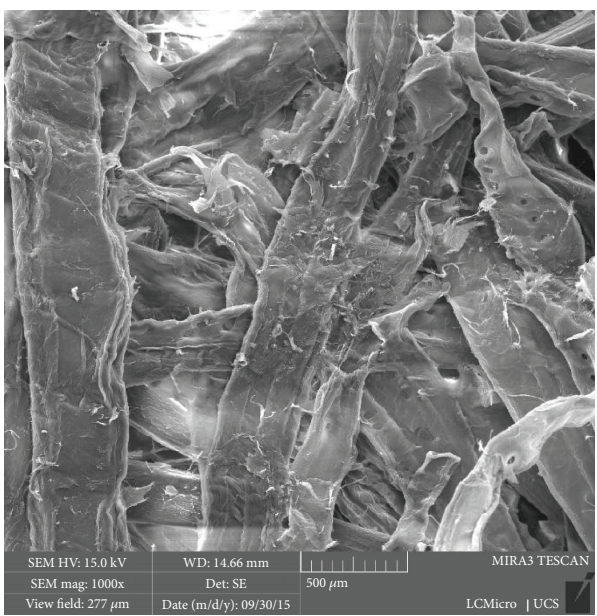

(d)

Figure 2: FEG-SEM micrograph of CE at 150x (a) and 1000x magnification (b). FEG-SEM micrograph of CP at 150x (c) and 1000x magnification $(\mathrm{d})$.

and subsequently vacuum freeze-dried. In their studies with aerogels of cellulose nanofibers, Zanini et al. [38] found apparent density values of $0.0240 \mathrm{~g} \cdot \mathrm{cm}^{-3}$ and a porosity of $97.2 \%$. The authors obtained freeze-dried aerogels derived from a suspension with $2.19 \%$ (wt\%) of cellulose nanofibres obtained by a mechanical process.

\subsection{Scanning Electron Microscopy with Field Emission Gun} (FEG-SEM). Figure 3 shows the microscopy images obtained from $\mathrm{CE}$ and $\mathrm{CP}$ aerogels. In Figures 3(a) and 3(c), the macroscopic structure of the aerogels is observed, and in Figures 3(b) and 3(d) it is possible to visualize the presence of fibers with diameters within the nanoscale range in the samples of the obtained aerogels. In this work, CNFs were obtained with diameters smaller than $71 \mathrm{~nm}$.

The morphology and properties of aerogels are theoretically related to sample freezing conditions, cellulose particle size, solid concentration in the suspension, surface loading, and the self-organizing behavior of the cellulose fibers during freeze-drying. In the micrographs of freeze-dried aerogels, the formation of a lamellar structure with fiber alignment was also observed. This was also reported by Pääkkö et al. [37] and Han et al. [39].

Freeze-dried aerogels presented a lamellar structure. During the freezing process, the ordered and porous structure is achieved by organizing the growing spaces of the ice crystals. Thus, it is important that this stage is carried out fast for the formation of small crystals, allowing the formation of the chains with cellulose microfibers, thus forming voids after freeze-drying [37].

According to Han et al. [39], the arrangements of hydrogen bonds play an important role in the self-organizing properties of the cellulose suspension. At concentrations ranging from 2.2 to $2.6 \%$, the spaces between the microfibers enable the formation of intra- and intermolecular hydrogen bonds, as well as the formation of Van der Walls forces, aligning them longitudinally during the freezing process, thus yielding a lamellar structure.

In the micrograph shown in Figure 3(c), the presence of fragments of larger fibers is observed in the $\mathrm{CP}$ aerogel when compared to microscopy of the CE aerogel (Figure 3(a)), mainly because $\mathrm{CP}$ has a longer fiber length. As such, larger 


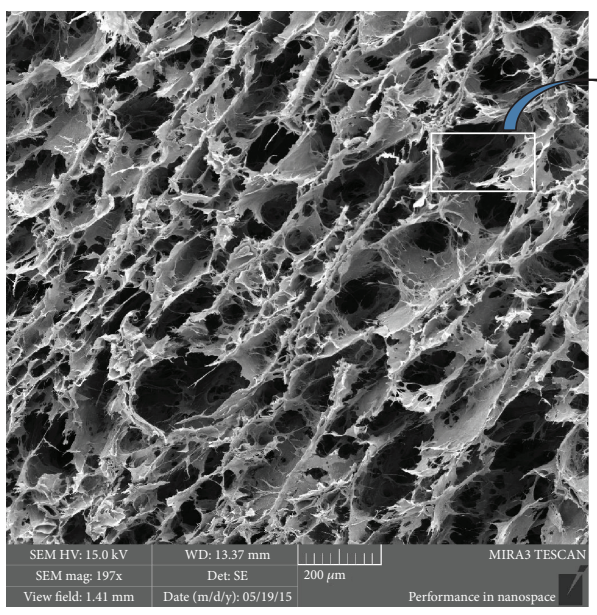

(a)

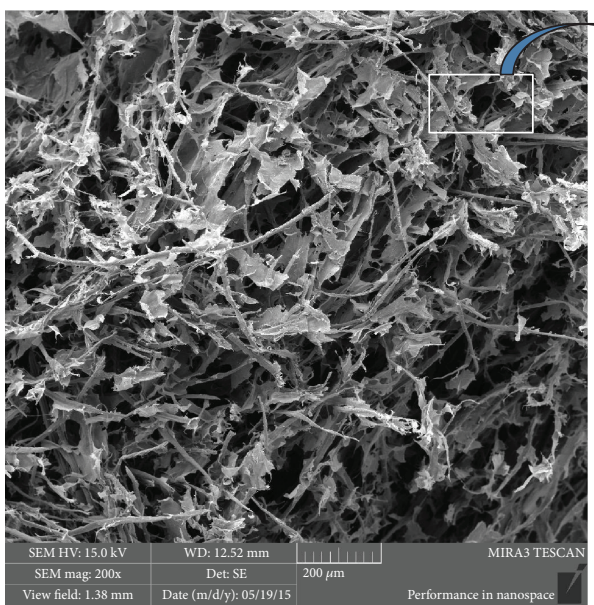

(c)

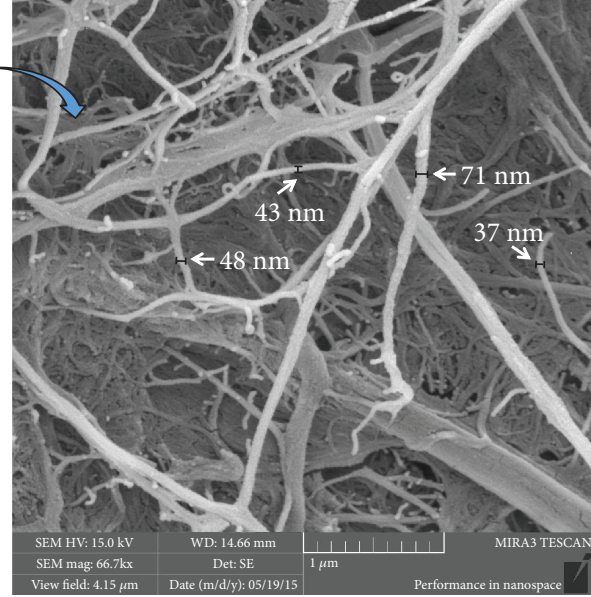

(b)

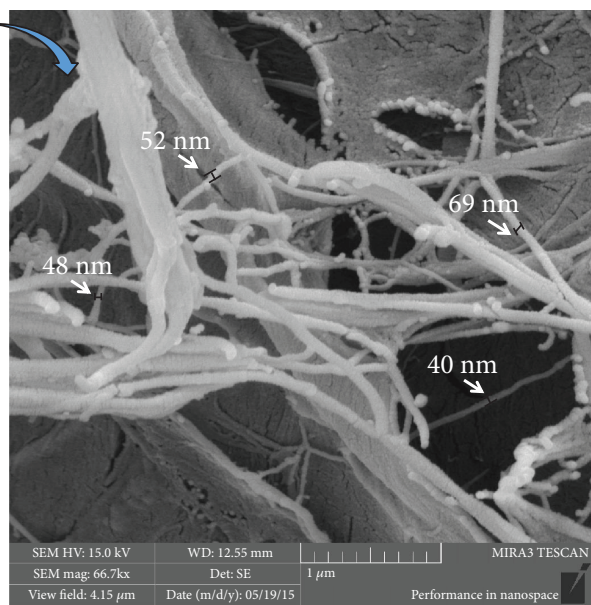

(d)

FIgURE 3: FEG-SEM micrographs of CE aerogel: lamellar structure (a) and nanofiber detail (b). FEG-SEM micrographs of CP aerogel: lamellar structure (c) and nanofiber detail (d).

fiber fragments may remain even after the fibrillation process, when compared to the aerogels from the CE suspension. Bassa et al. [40] observed the same behavior for Pinus sp. and Eucalyptus sp. fibers. The authors report that Pinus sp. fibrils are longer than Eucalyptus fibers.

3.5. Compressive Strength Tests. The compressive strength tests were performed with aerogels with and without chemical treatment. The results obtained from the compressive strength test with $50 \%$ deformation have the following values: $60.26 \mathrm{kPa}$ (CE aerogel), $69.35 \mathrm{kPa}$ (CP aerogel), $89.76 \mathrm{kPa}$ (CE aerogel with MTMS), and $128.77 \mathrm{kPa}$ (CP aerogel with MTMS).

The chemical treatment with MTMS provided higher compressive strength for the aerogels: an increase of $48.95 \%$ for the CE aerogel and an increase of $85.68 \%$ for the CP aerogel. Zhang et al. [4], also observed greater compressive strength of CNF sponges after chemical treatment with MTMS. According to the authors, this effect was attributed to the increasing contribution of the polysiloxane layer at the NFC surface. Pääkkö et al. [37] obtained values of
$200 \mathrm{kPa}$ for CNF aerogels in the test of resistance to compression, with $70 \%$ deformation.

Stress-strain curves under compression are shown in Figure 4. Linear elastic regions can be observed in the stress-strain curves. Gradual transition from linear to nonlinear, as well as densification behavior, that is, the collapse of empty spaces, was also seen. This behavior is characteristic of porous materials, and it was also observed by Sehaqui et al. [41] and Karadagli et al. [42].

The graph shows that the aerogels from CP with and without treatment presented higher values of compressive strength when compared to $\mathrm{CE}$ aerogels. According to Kim et al. [43], the compression of the fiber network of the CNF aerogel takes place upon the bending of individual fibers or by the breakage of interfiber bonds, as well as by the loss of friction between adjacent fibers and the physical entanglement of the fibers. Also, according to Sehaqui et al. [41], at low strains the stress-strain behavior is linear and elastic in nature. Deformation is expected to be primarily due to elastic cell wall bending at large strains in the densification region, where the cell walls are in close contact to each other and 


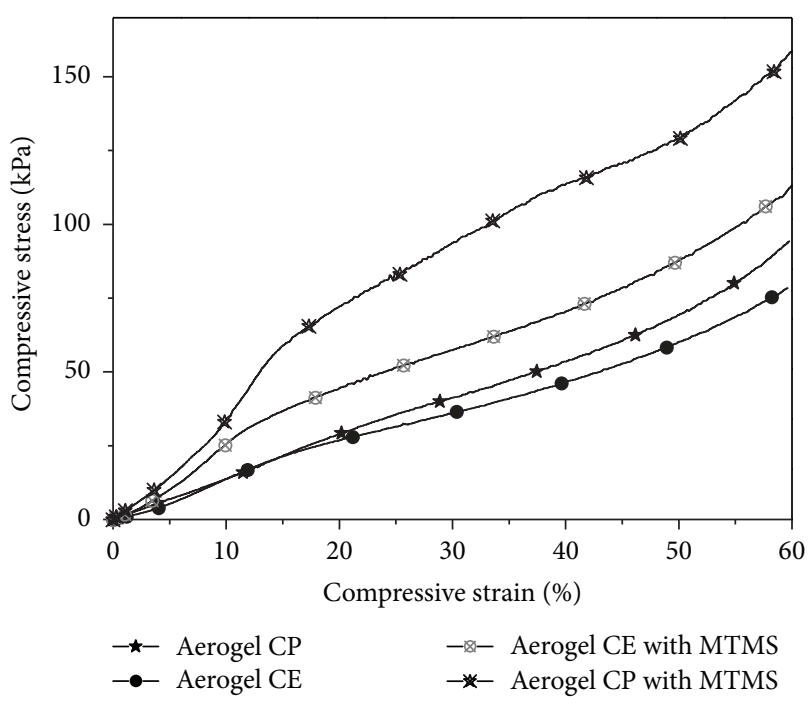

FIGURE 4: Compressive stress-strain curve of aerogels.

there is a steep rise in stress levels with little further strain. Therefore, it could be suggested that the larger fiber fragments of the fibrils in CP aerogels provide increased compressive strength in comparison with CE aerogels, which possess seemingly smaller and bent fibrils, as seen in the SEM micrographs in Figure 3.

3.6. Fourier Transform Infrared Spectroscopy (FTIR). Figures 5(a) and 5(b) show the spectra obtained from the cellulose source and their aerogels before and after chemical treatment. In the samples with chemical treatment, it is possible to observe the appearance of new bands, characteristics of the MTMS silane.

It was not possible to identify chemical changes related to mechanical fibrillation or to the freeze-drying process in these samples. Characteristic bands of the cellulose fibers were observed in the cellulose samples and in their respective aerogels without chemical treatment.

The band at $3300 \mathrm{~cm}^{-1}$ is related to the $\mathrm{O}-\mathrm{H}$ stretching vibration of the hydroxyl groups. The peak at $1596 \mathrm{~cm}^{-1}$ is associated to $\mathrm{C}=\mathrm{C}, \mathrm{C}-\mathrm{O}$ stretching, or to the bending vibrations of different groups present in lignin. The peak at $1318 \mathrm{~cm}^{-1}$ is attributed to the bending vibration of the $\mathrm{C}-\mathrm{H}$ and $\mathrm{C}-\mathrm{O}$ groups of the aromatic ring in polysaccharides. The band at $1032 \mathrm{~cm}^{-1}$ is characteristic of the $\mathrm{C}-\mathrm{O}$ vibration of cellulose, and the peak at $896 \mathrm{~cm}^{-1}$ is related to amorphous cellulose vibration, that is, glucose ring stretch [44-49].

After chemical treatment with MTMS, the characteristic vibrations of silane were identified at $1265 \mathrm{~cm}^{-1}$ and $1267 \mathrm{~cm}^{-1}$, related to the deformation of the $\mathrm{CH}$ bond of the methyl group. The peaks at $890 \mathrm{~cm}^{-1}$ and $893 \mathrm{~cm}^{-1}$ were attributed to the $\mathrm{Si}-\mathrm{OH}$ bond stretching vibrations, and the peaks at $776 \mathrm{~cm}^{-1}$ and $777 \mathrm{~cm}^{-1}$ were related to the absorption bands of the stretching vibrations of the $\mathrm{Si}-\mathrm{C}$ bond and/or the stretching vibrations of the $\mathrm{Si}-\mathrm{O}$ bond $[50,51]$.

3.7. Water Contact Angle Measurement. The contact angle measurement was carried out with aerogels with and without chemical treatment. The hydrophobic character of the aerogels was determined by measuring the contact angle of their surface with water. It was not possible to perform any measurement during the test of aerogels without silane treatment, since the water was sorbed immediately after its addition to the surface. Figure 6(a) shows the test performed. The contact angles obtained for the aerogels with MTMS were $135.82^{\circ} \pm 2.31$ and $134.81^{\circ} \pm 1.32$, for $\mathrm{CE}$ and $\mathrm{CP}$, respectively. These results allowed the identification of the hydrophobic character in the aerogels.

According to Wan et al. [52] and Xiao et al. [48], the modification by silane contributes to the formation of a low-energy surface of the cellulose aerogel due to the replacement of surface hydroxyl groups in the cellulose with hydrophobic groups. Xiao et al. [48] obtained a value of $135^{\circ}$ for pine needle nanofiber aerogels obtained by the treatment of trimethylchlorosilane through vapor phase deposition.

3.8. Sorption Tests in Homogeneous Medium. Sorption tests in homogeneous medium with water were carried out with the samples with and without chemical treatment. Results obtained for the samples without chemical treatment have values of $29.995 \pm 0.078 \mathrm{~g} \cdot \mathrm{g}^{-1}$ and $33.920 \pm 0.109 \mathrm{~g} \cdot \mathrm{g}^{-1}$ for the $\mathrm{CE}$ and $\mathrm{CP}$ aerogels, respectively. For the samples treated with MTMS, the sorption values found were $0.173 \pm$ $0.003 \mathrm{~g} \cdot \mathrm{g}^{-1}$ for the CE aerogel and $0.491 \pm 0.005 \mathrm{~g} \cdot \mathrm{g}^{-1}$ for the $\mathrm{CP}$ aerogel. This shows that the chemical treatment used provided low affinity of the material with water.

Sorption tests in homogeneous medium with oil were carried out with the samples with and without chemical treatment. Results obtained for the samples without chemical treatment have values of $20.796 \pm 2.80 \mathrm{~g} \cdot \mathrm{g}^{-1}$ and $17.518 \pm$ $2.272 \mathrm{~g} \cdot \mathrm{g}^{-1}$ for the CE and CP aerogels, respectively. After chemical treatment with MTMS, the aerogels showed an increase in the oil sorption capacity, being 24.32 \pm $2.519 \mathrm{~g} \cdot \mathrm{g}^{-1}$ for the CE aerogel and $22.829 \pm 1.530 \mathrm{~g} \cdot \mathrm{g}^{-1}$ for the CP aerogel.

The oil sorption process in cellulose aerogels is related to the interiority of the porous structure of the material (large surface area and large number of capillary channels internally), as well as to the hydrophobic characteristic of the surface [53].

CE aerogels presented a higher amount of oil sorbed, while having the lowest density. The lower the density of the material, the greater the amount of voids, thus the tendency to sorb more oil. According to Rengasamy et al. [54], the sorption capacity is influenced by the density of the fibers. Lower values of density show lower compaction of aerogels and greater availability of free spaces for the oil to be sorbed into the material.

3.9. Sorption Tests in Heterogeneous Medium (Water/Oil). Sorption capacity in heterogeneous medium of chemically treated aerogels was $21.543 \pm 0.126 \mathrm{~g} \cdot \mathrm{g}^{-1}$ and $21.303 \pm$ $0.257 \mathrm{~g} \cdot \mathrm{g}^{-1}$ for the CE and CP aerogels, respectively. As such, the efficiency in oil removal was between 88.5 and $93.3 \%$. The hydrophobic characteristic on the surface of the aerogels provides the selectivity of the sorbent in the presence of the heterogeneous medium of water and oil. Figure 6(b) shows the performed tests. 


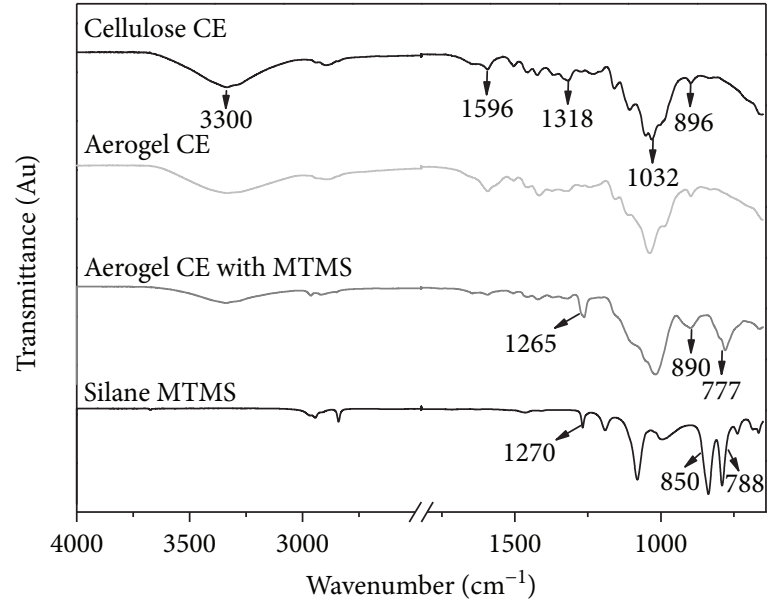

(a)

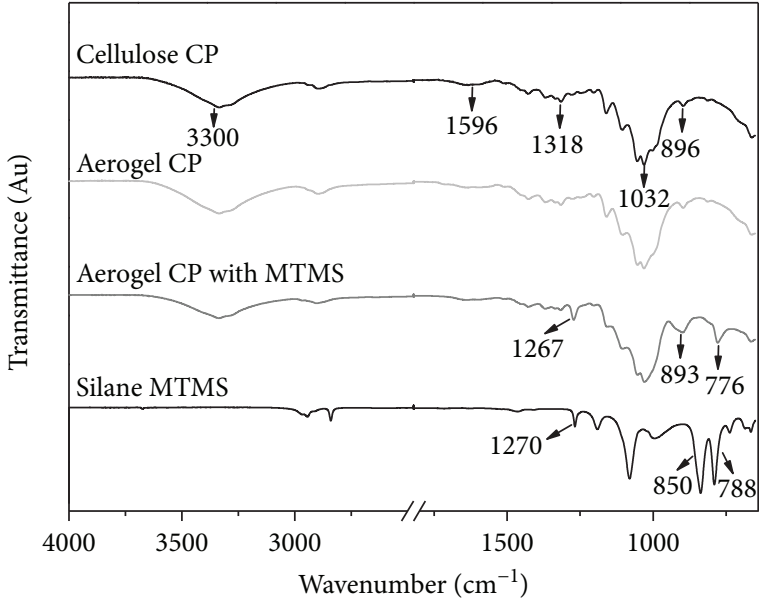

(b)

FIGURE 5: FTIR spectra: (a) CE cellulose and CE aerogel with and without MTMS. (b) CP cellulose and CE aerogel with and without MTMS.
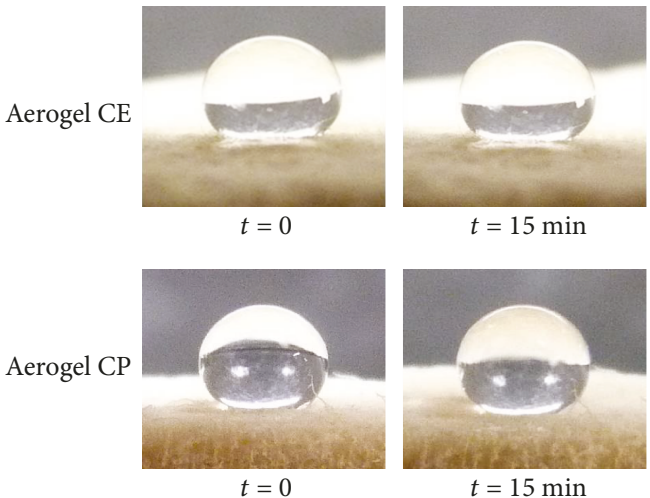

$t=15 \mathrm{~min}$

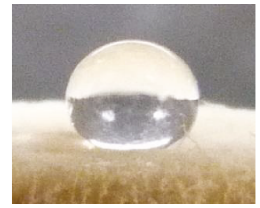

$t=15 \mathrm{~min}$

(a)
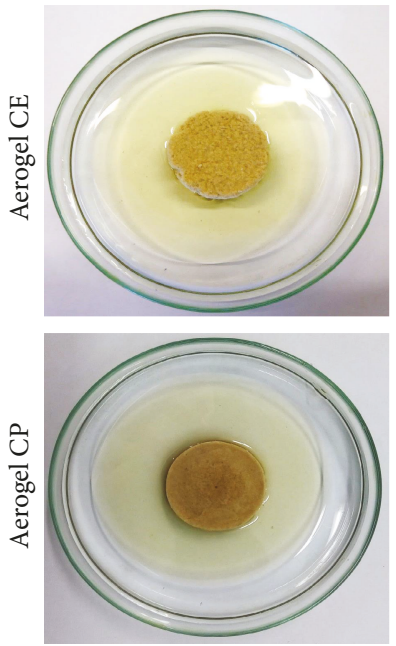

$$
t=0
$$

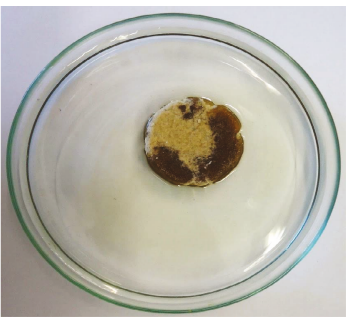

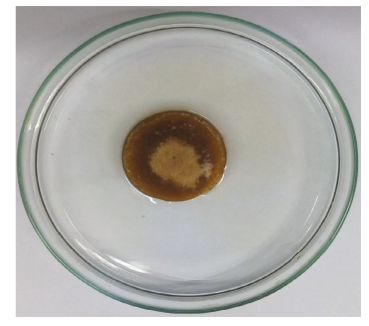

$t=10 \mathrm{~min}$

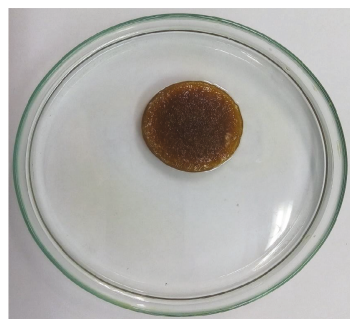

$t=15 \mathrm{~min}$

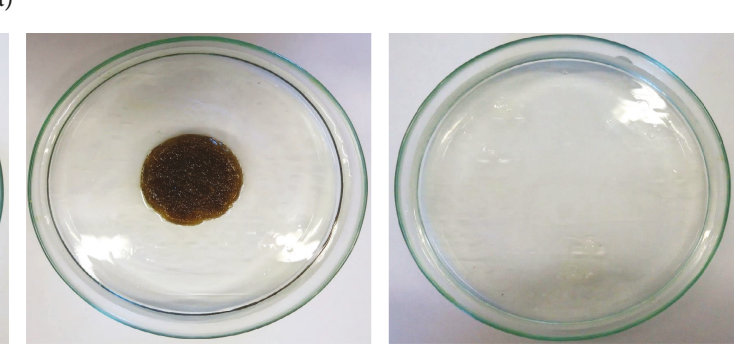

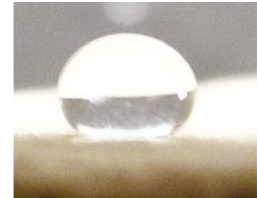

$t=30 \mathrm{~min}$

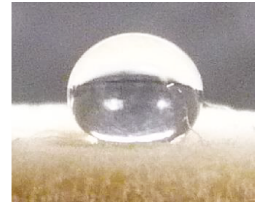

$t=30 \mathrm{~min}$

(b)

Figure 6: (a) Contact angle measurements from $t=0$ to $t=30$. (b) Sorption capacity tests from $t=0$ to $t=15$ min in heterogeneous medium (oil/water). 
Jin et al. [24] obtained aerogels from newspaper waste. This residue was composed of $50.1 \%$ cellulose and $18.1 \%$ lignin. They performed a chemical treatment in the aerogels by vapor deposition of trimethylchlorosilane. The aerogels presented an adsorption capacity ranging from 11 to $22 \mathrm{~g} \cdot \mathrm{g}^{-1}$ for motor oil and organic solvents such as chloroform, for example.

Zanini et al. [25] obtained aerogels of bleached CNFs of Eucalyptus sp. with a sorption capacity in heterogeneous medium of $16.78 \mathrm{~g}^{-g^{-1}}$ and an oil removal efficiency of $87.9 \%$. The presence of lignin in unbleached cellulose aerogels favored a higher sorption capacity. This was also observed by Payne et al. [55], who verified that the presence of lignin in cellulose fibers resulted in a $10 \%$ increase in the sorption of the oil, attributing to the higher affinity of lignin with oil because of its aromatic nature.

In their studies, based on different methods of silanization, Lazzari et al. [26] obtained aerogels with 1.5\% of unbleached CNFs of Pinus elliottii, with a sorption capacity in heterogeneous medium of $68.42 \mathrm{~g}^{-\mathrm{g}^{-1}}$. The present study found lower values in relation to the sorption capacity found by Lazzari et al. [26]. However, it was possible to observe that the silanization process provided greater mechanical resistance to the aerogels obtained.

\section{Conclusions}

Fibrillation was an efficient process for obtaining CNFs from the two cellulose sources used. When compared to chemical processes, it does not generate hazardous chemical residues.

The presence of lignin in the unbleached samples did not alter the overall properties of the aerogels obtained, thus allowing the use of a raw material of lower cost and lower environmental impact for the production of aerogels. The chemical treatment of the aerogels was efficient, which provided the oil selectivity of the material in heterogeneous medium, as well as a greater compressive strength when compared to their neat counterparts. The CP aerogel presented the highest compressive strength, while the CE aerogel presented the highest sorption capacity. In conclusion, unbleached cellulose fibers are a viable alternative for use as oil sorbents in aqueous media.

\section{Data Availability}

The data used to support the findings of this study are included within the article.

\section{Conflicts of Interest}

The authors declare that there is no conflict of interests regarding the publication of this paper.

\section{Acknowledgments}

The authors would like to thank Conselho Nacional de Pesquisa e Desenvolvimento $(\mathrm{CNPq})$ and Secretaria da Ciência, Inovação e Desenvolvimento do Rio Grande do Sul (SCT/RS) for their support.

\section{References}

[1] Agência Nacional do Petróleo-ANP, "Brazilian statistical yearbook of petroleum, natural gas and biofuels," 2015, May 2018 http://www.anp.gov.br/wwwanp/publicacoes/anuarioestatistico/2440-anuario-estatistico-2015.

[2] Internacional Tanker Owners Pollution Federation-ITOPF, “Oil tanker spill statistics 2016," vol. 437, 2017, September 2017 http://www.itopf.com/knowledge-resources/datastatistics/statistics/.

[3] J. T. Korhonen, M. Kettunen, R. H. A. Ras, and O. Ikkala, "Hydrophobic nanocellulose aerogels as floating, sustainable, reusable, and recyclable oil absorbents," ACS Applied Materials \& Interfaces, vol. 3, no. 6, pp. 1813-1816, 2011.

[4] Z. Zhang, G. Sèbe, D. Rentsch, T. Zimmermann, and P. Tingaut, "Ultralightweight and flexible silylated nanocellulose sponges for the selective removal of oil from water," Chemistry of Materials, vol. 26, no. 8, pp. 2659-2668, 2014.

[5] H. Sai, R. Fu, L. Xing et al., "Surface modification of bacterial cellulose aerogels' web-like skeleton for oil/water separation," ACS Applied Materials \& Interfaces, vol. 7, no. 13, pp. 73737381, 2015.

[6] O. Karatum, S. A. Steiner III, J. S. Griffin, W. Shi, and D. L. Plata, "Flexible, mechanically durable aerogel composites for oil capture and recovery," ACS Applied Materials \& Interfaces, vol. 8, no. 1, pp. 215-224, 2015.

[7] M. A. Meyers, P.-Y. Chen, A. Y.-M. Lin, and Y. Seki, "Biological materials: structure and mechanical properties," Progress in Materials Science, vol. 53, no. 1, pp. 1-206, 2008.

[8] K. Yuwawech, J. Wootthikanokkhan, and S. Tanpichai, "Effects of two different cellulose nanofiber types on properties of poly(vinyl alcohol) composite films," Journal of Nanomaterials, vol. 2015, Article ID 908689, 10 pages, 2015.

[9] N. Mahfoudhi and S. Boufi, "Nanocellulose as a novel nanostructured adsorbent for environmental remediation: a review," Cellulose, vol. 24, no. 3, pp. 1171-1197, 2017.

[10] M. Hassanzadeh, R. Sabo, A. Rudie, R. Reiner, R. Gleisner, and G. S. Oporto, "Nanofibrillated cellulose from Appalachian hardwoods logging residues as template for antimicrobial copper," Journal of Nanomaterials, vol. 2017, Article ID 2102987, 14 pages, 2017.

[11] Indústria Brasileira de Árvores-IBÁ, "Statictics of the Brazilian tree industry,” 2017, September 2017 http://iba.org/images/ shared/Biblioteca/IBA_RelatorioAnual2017.pdf.

[12] G. Chinga-Carrasco, "Cellulose fibres, nanofibrils and microfibrils: the morphological sequence of MFC components from a plant physiology and fibre technology point of view," Nanoscale Research Letters, vol. 6, no. 1, p. 417, 2011.

[13] S. T. Nguyen, J. Feng, N. T. le et al., "Cellulose aerogel from paper waste for crude oil spill cleaning," Industrial \& Engineering Chemistry Research, vol. 52, no. 51, pp. 18386-18391, 2013.

[14] L. Brinchi, F. Cotana, E. Fortunati, and J. M. Kenny, "Production of nanocrystalline cellulose from lignocellulosic biomass: technology and applications," Carbohydrate Polymers, vol. 94, no. 1, pp. 154-169, 2013.

[15] H. P. S. Abdul Khalil, Y. Davoudpour, M. N. Islam et al., "Production and modification of nanofibrillated cellulose using various mechanical processes: a review," Carbohydrate Polymers, vol. 99, pp. 649-665, 2014.

[16] Y.-Y. Li, B. Wang, M.-G. Ma, and B. Wang, "Review of recent development on preparation, properties, and applications of 
cellulose-based functional materials," International Journal of Polymer Science, vol. 2018, Article ID 8973643, 18 pages, 2018.

[17] M. T. Postek, R. J. Moon, A. W. Rudie, and M. A. Biodeau, Production and Applications of Cellulose Nanomaterials, TAPPI Press, Estados Unidos da América, 2013.

[18] M. Delgado-Aguilar, Q. Tarrés, M. À. Pèlach, P. Mutjé, and P. Fullana-i-Palmer, "Are cellulose nanofibers a solution for a more circular economy of paper products?," Environmental Science \& Technology, vol. 49, no. 20, pp. 12206-12213, 2015.

[19] D. Klemm, F. Kramer, S. Moritz et al., "Nanocelluloses: a new family of nature-based materials," Angewandte Chemie International Edition, vol. 50, no. 24, pp. 5438-5466, 2011.

[20] J. Nemoto, T. Saito, and A. Isogai, "Simple freeze-drying procedure for producing nanocellulose aerogel-containing, high-performance air filters," ACS Applied Materials \& Interfaces, vol. 7, no. 35, pp. 19809-19815, 2015.

[21] M. A. Aegerter, N. Leventis, and M. M. Koebel, Aerogels Handbook, Advances in Sol-Gel Derived Materials and Technologies, Springer New York, Nova York, 2011.

[22] N. T. Cervin, C. Aulin, P. T. Larsson, and L. Wågberg, "Ultra porous nanocellulose aerogels as separation medium for mixtures of oil/water liquids," Cellulose, vol. 19, no. 2, pp. 401-410, 2012.

[23] R. Wahi, L. A. Chuah, T. S. Y. Choong, Z. Ngaini, and M. M. Nourouzi, "Oil removal from aqueous state by natural fibrous sorbent: an overview," Separation and Purification Technology, vol. 113, pp. 51-63, 2013.

[24] C. Jin, S. Han, J. Li, and Q. Sun, "Fabrication of cellulose-based aerogels from waste newspaper without any pretreatment and their use for absorbents," Carbohydrate Polymers, vol. 123, pp. 150-156, 2015.

[25] M. Zanini, A. Lavoratti, L. K. Lazzari et al., "Producing aerogels from silanized cellulose nanofiber suspension," Cellulose, vol. 24, no. 2, pp. 769-779, 2017.

[26] L. K. Lazzari, V. B. Zampieri, M. Zanini, A. J. Zattera, and C. Baldasso, "Sorption capacity of hydrophobic cellulose cryogels silanized by two different methods," Cellulose, vol. 24, no. 8, pp. 3421-3431, 2017.

[27] S. T. Nguyen, J. Feng, S. K. Ng, J. P. W. Wong, V. B. C. Tan, and H. M. Duong, "Advanced thermal insulation and absorption properties of recycled cellulose aerogels," Colloids and Surfaces A: Physicochemical and Engineering Aspects, vol. 445, pp. 128-134, 2014.

[28] Y. Chen, J. Wan, X. Zhang, Y. Ma, and Y. Wang, "Effect of beating on recycled properties of unbleached eucalyptus cellulose fiber," Carbohydrate Polymers, vol. 87, no. 1, pp. 730-736, 2012.

[29] J. L. Gomide, J. L. Colodette, R. C. d. Oliveira, and C. M. Silva, "Technological characterization of the new generation of Eucalyptus clones in Brazil for kraft pulp production," Revista Árvore, vol. 29, no. 1, pp. 129-137, 2005.

[30] U. Klock, G. I. B. Muñiz, J. H. Anzaldo, and A. Andrade, Química da Madeira, Man. Didat, Dep. Eng. e Tecnlogia Florest. - Fupef Do Paraná, 2005.

[31] D. Klemm, B. Heublein, H. P. Fink, and A. Bohn, "Cellulose: fascinating biopolymer and sustainable raw material," Angewandte Chemie International Edition, vol. 44, no. 22, pp. 3358-3393, 2005.

[32] Y. Peng, D. J. Gardner, and Y. Han, "Drying cellulose nanofibrils: in search of a suitable method," Cellulose, vol. 19, no. 1, pp. 91-102, 2012.
[33] S. Kalia, S. Boufi, A. Celli, and S. Kango, "Nanofibrillated cellulose: surface modification and potential applications," Colloid \& Polymer Science, vol. 292, no. 1, pp. 5-31, 2014.

[34] M. V. Zimmermann, C. Borsoi, A. Lavoratti, M. Zanini, A. J. Zattera, and R. M. Santana, "Drying techniques applied to cellulose nanofibers," Journal of Reinforced Plastics and Composites, vol. 35, no. 8, pp. 628-643, 2016.

[35] J. Shi, L. Lu, W. Guo, M. Liu, and Y. Cao, "On preparation, structure and performance of high porosity bulk cellulose aerogel," Plastics, Rubber and Composites, vol. 44, no. 1, pp. 26-32, 2015.

[36] W. Chen, Q. Li, Y. Wang et al., "Comparative study of aerogels obtained from differently prepared nanocellulose fibers," ChemSusChem, vol. 7, no. 1, pp. 154-161, 2014.

[37] M. Pääkkö, J. Vapaavuori, R. Silvennoinen et al., "Long and entangled native cellulose I nanofibers allow flexible aerogels and hierarchically porous templates for functionalities," Soft Matter, vol. 4, no. 12, p. 2492, 2008.

[38] M. Zanini, A. Lavoratti, M. V. G. Zimmermann et al., “Aerogel preparation from short cellulose nanofiber of the Eucalyptus species," Journal of Cellular Plastics, vol. 53, no. 5, pp. 503512, 2017.

[39] J. Han, C. Zhou, Y. Wu, F. Liu, and Q. Wu, "Self-assembling behavior of cellulose nanoparticles during freeze-drying: effect of suspension concentration, particle size, crystal structure, and surface charge," Biomacromolecules, vol. 14, no. 5, pp. 1529-1540, 2013.

[40] A. G. M. C. Bassa, F. G. S. Junior, and V. M. Sacon, "Mixtures of Eucalyptus grandis $\times$ Eucalyptus urophylla and Pinus taeda wood chips for kraft pulp production by Lo-Solids ${ }^{\circledR}$ process," Scientia Forestalis, vol. 75, pp. 19-29, 2007.

[41] H. Sehaqui, M. Salajková, Q. Zhou, and L. A. Berglund, "Mechanical performance tailoring of tough ultra-high porosity foams prepared from cellulose I nanofiber suspensions," Soft Matter, vol. 6, no. 8, p. 1824, 2010.

[42] I. Karadagli, B. Schulz, M. Schestakow, B. Milow, T. Gries, and L. Ratke, "Production of porous cellulose aerogel fibers by an extrusion process," Journal of Supercritical Fluids, vol. 106, pp. 105-114, 2015.

[43] C. H. Kim, H. J. Youn, and H. L. Lee, "Preparation of cross-linked cellulose nanofibril aerogel with water absorbency and shape recovery," Cellulose, vol. 22, no. 6, pp. 3715-3724, 2015.

[44] C. M. Popescu, G. Singurel, M. C. Popescu, C. Vasile, D. S. Argyropoulos, and S. Willför, "Vibrational spectroscopy and $\mathrm{X}$-ray diffraction methods to establish the differences between hardwood and softwood," Carbohydrate Polymers, vol. 77, no. 4, pp. 851-857, 2009.

[45] I. M. De Rosa, J. M. Kenny, M. Maniruzzaman et al., "Effect of chemical treatments on the mechanical and thermal behaviour of okra (Abelmoschus esculentus) fibres," Composites Science and Technology, vol. 71, no. 2, pp. 246-254, 2011.

[46] M. Poletto, H. Ornaghi Júnior, and A. Zattera, "Native cellulose: structure, characterization and thermal properties," Materials, vol. 7, no. 9, pp. 6105-6119, 2014.

[47] N. S. Lani, N. Ngadi, A. Johari, and M. Jusoh, "Isolation, characterization, and application of nanocellulose from oil palm empty fruit bunch fiber as nanocomposites," Journal of Nanomaterials, vol. 2014, Article ID 702538, 9 pages, 2014.

[48] S. Xiao, R. Gao, Y. Lu, J. Li, and Q. Sun, "Fabrication and characterization of nanofibrillated cellulose and its aerogels 
from natural pine needles," Carbohydrate Polymers, vol. 119, pp. 202-209, 2015.

[49] A. Lavoratti, L. C. Scienza, and A. J. Zattera, "Dynamicmechanical and thermomechanical properties of cellulose nanofiber/polyester resin composites," Carbohydrate Polymers, vol. 136, pp. 955-963, 2016.

[50] N. Özmen, N. Sami Çetin, P. Tingaut, and G. Sèbe, "Transesterification reaction between acetylated wood and trialkoxysilane coupling agents," Journal of Applied Polymer Science, vol. 105, no. 2, pp. 570-575, 2007.

[51] Y. Zhang, T. Nypelö, C. Salas, J. Arboleda, I. C. Hoeger, and O. J. Rojas, "Cellulose nanofibrils: from strong materials to bioactive surfaces," Journal of Renewable Materials, vol. 1, no. 3, pp. 195-211, 2013.

[52] C. Wan, Y. Lu, Y. Jiao, C. Jin, Q. Sun, and J. Li, "Fabrication of hydrophobic, electrically conductive and flame-resistant carbon aerogels by pyrolysis of regenerated cellulose aerogels," Carbohydrate Polymers, vol. 118, pp. 115-118, 2015.

[53] H. Zhang, Y. Li, Y. Xu et al., "Versatile fabrication of a superhydrophobic and ultralight cellulose-based aerogel for oil spillage clean-up," Physical Chemistry Chemical Physics, vol. 18, no. 40, pp. 28297-28306, 2016.

[54] R. S. Rengasamy, D. Das, and C. Praba Karan, "Study of oil sorption behavior of filled and structured fiber assemblies made from polypropylene, kapok and milkweed fibers," Journal of Hazardous Materials, vol. 186, no. 1, pp. 526-532, 2011.

[55] K. C. Payne, C. D. Jackson, C. E. Aizpurua, O. J. Rojas, and M. A. Hubbe, "Oil spills abatement: factors affecting oil uptake by cellulosic fibers," Environmental Science \& Technology, vol. 46, no. 14, pp. 7725-7730, 2012. 


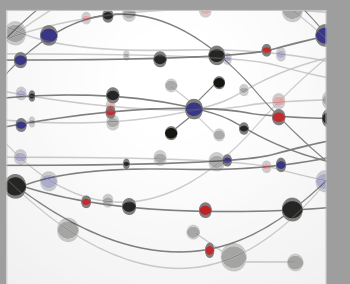

The Scientific World Journal
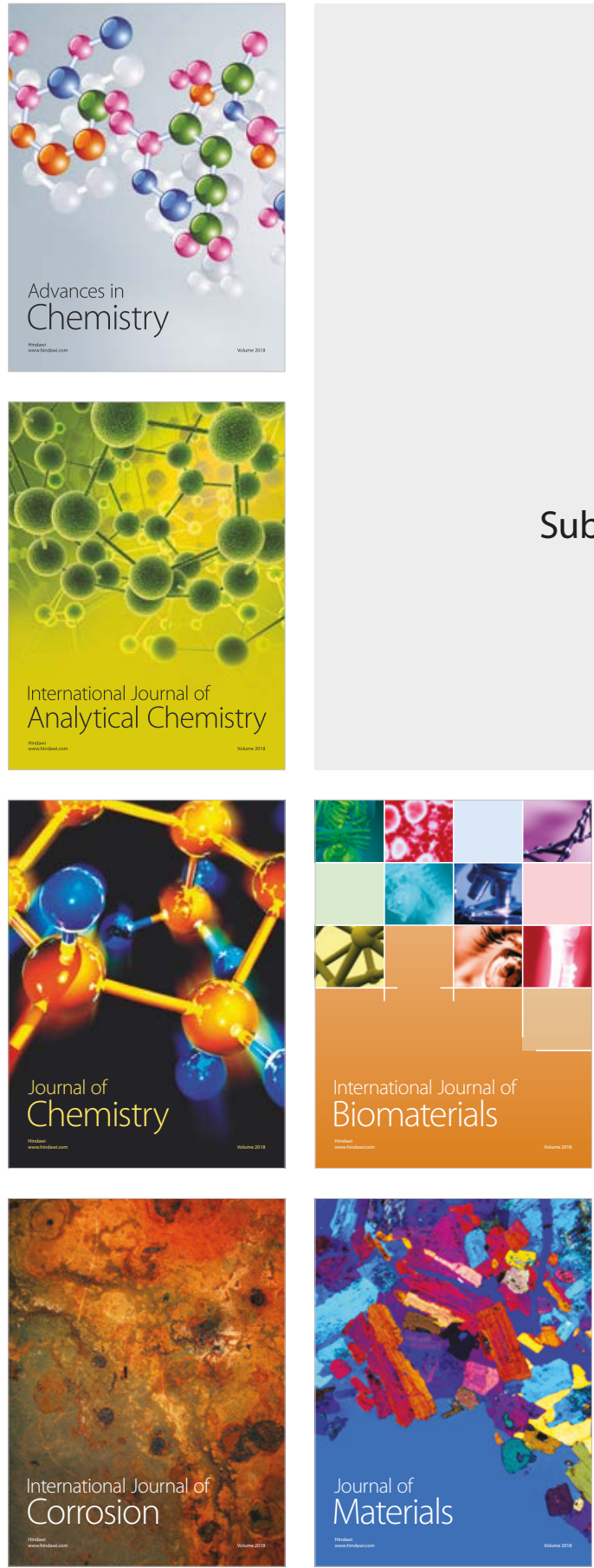

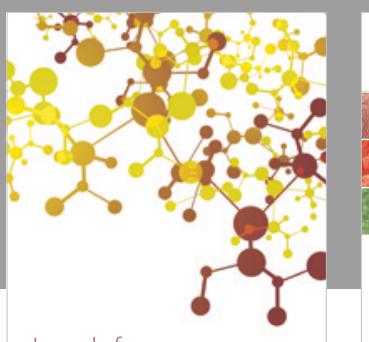

Journal of

Applied Chemistry
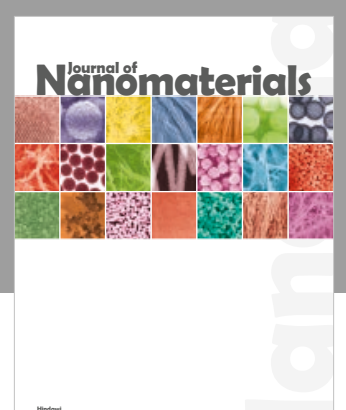

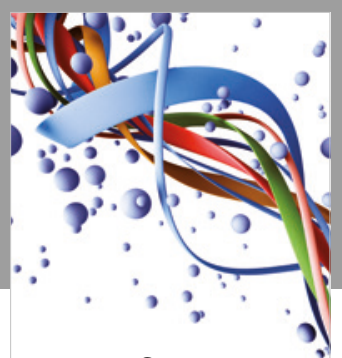

Scientifica

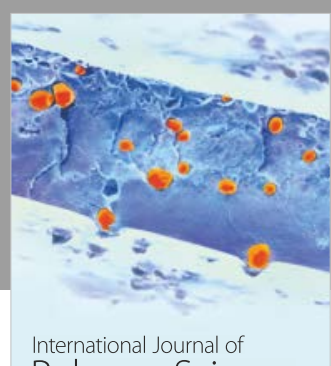

Polymer Science

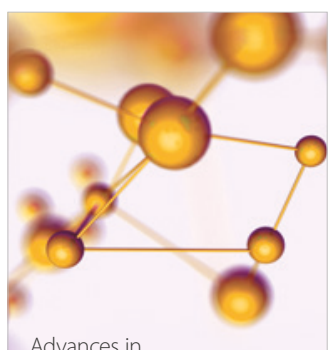

Physical Chemistry
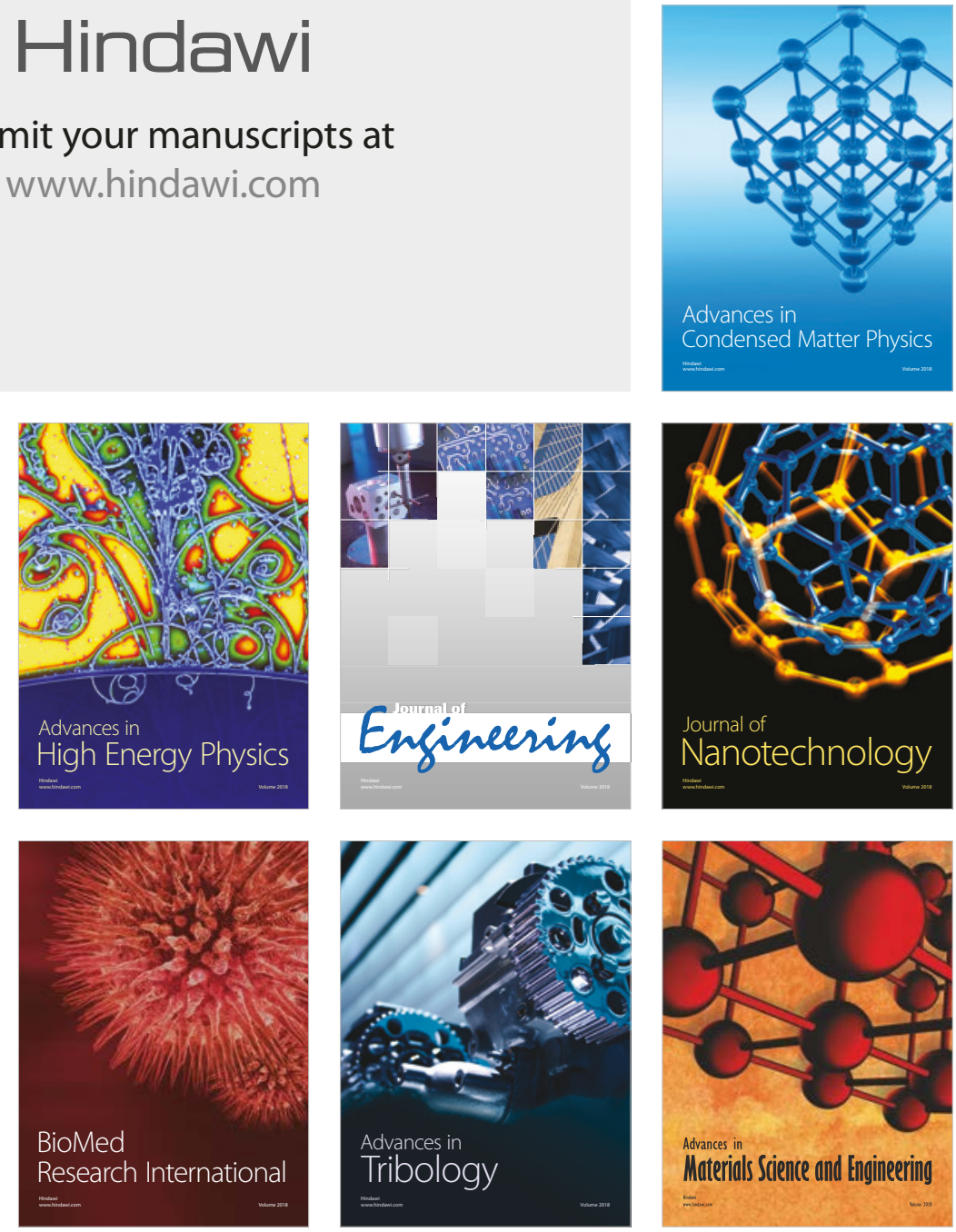